\title{
The Olfactory Experience: constants and cultural variables
}

\section{Joël CANDAU}

candau@,unice.fr

Laboratoire d'Anthropologie "Mémoire, Identité, et Cognition Sociale" (LAMIC)

Université de Nice-Sophia Antipolis

98 Bd. Edouard Herriot, B.P. 209

06204 Nice Cedex 3

\begin{abstract}
Odor and olfaction anthropology explores four lines of research which, in many cases, may overlap: the variability of the olfactory perception, olfactory skills and know-how, odor use, and odor representations. My proposal here is to deal with the first one, trying to answer the following question: is olfactory perception a phenomenon resulting solely from the biological organization of the human being, in such a way that it does not know other variations than the ones due to nature? Or, on the contrary, can we show different kinds of olfaction culturally determined or, at least, environmental influences resulting in significant perceptual differences among groups, societies, cultures, etc.?

In the first part of the text, I will deal with the invariants (or universals). In the second, I will insist on the cultural types of olfaction. In the third and last part, I will advance the following proposal: beyond the discussion on the roles that nature and culture play in human olfaction, we can sustain that naturally and culturally, there is a way of smelling characteristic of our species. Finally, I will conclude with two examples of the symbolic treatment characteristic of the olfactory human experience.
\end{abstract}

\section{Keywords}

culture; human olfactory experience; memory; nature; olfactory harmony; olfactory melody;

We are all familiar with the following expressions : "Still waters run deep"; "Del agua mansa me libre Dios, que de la brava me libro yo"; "Méfiez-vous de l'eau qui dort!". In fact, many cultures are perplexed by or have a deep suspicion of still water, in part because of its smell. In Provence, for example, an unpleasant person would be referred to as "meichant como d'aigo de nai", or " as nasty as the pestilent water of a pond". Is this negative attitude toward the smell of stagnant water one of the olfactory constants which are held by every member of our species? Or, on the contrary, does it represent an attitude which varies greatly from one society to another? I imagine that the answer to this type of question for experts in the problems of water and its treatment, is extremely important in the light of growing public concern with unpleasant smells. If our sensitivity in this regard is simply a biological response, the solutions needed to render the smell pleasant, or at the very least tolerable, will work for every human on the planet. On the other hand, if our sensitivity is based on cultural influences, you will need to find solutions specifically tailored to different cultures.

At the risk of disappointing you, I'm not going to focus on the concept of our sensibility to the smell of water. My research has not focussed on this extremely subtle smell. Rather, I will talk about the general question of the variability of olfactory perception, and propose an answer to the following question: is olfactory perception strictly the result of human physiology, varying 
only in response to natural conditions? Or is it possible to consider the impact of culture on olfactory responses, that is, to take into account environmental variables which create different responses among individuals, groups, societies, cultures, and so on? In responding to this question I will refer principally to a survey I conducted among various professions which call for a certain olfactory expertise: perfumers, oenologists, chefs, forensic pathologists, nurses, and firemen.

I will begin by introducing universals present in all olfactory experiences. I will then discuss culturally influenced forms of olfaction and conclude by proposing that, the nature/culture debate aside, one can claim that naturally as well as culturally, our way of smelling is a hallmark of our species.

\section{CONSTANTS}

The sense of smell, it must be acknowledged, is an extremely primitive one (creatures as simple as bacteria have a sense of smell); it came into existence early in evolution, and it appears very soon in individual development (from a prenatal ${ }^{\mathrm{iii}}$ and neonatal ontogenetic standpoint). For these reasons it can be said to involve our deepest nature, our animal and sexual instincts, which is why it has long been discredited by many philosophers and the Catholic Church. As an "animal" instinct, it should be considered the most "natural" instinct of all. Consequently, if we appeal to the canonic distinction between nature (which is the stage of universal constants) and culture (which is the stage of societal rules) we would have to be prepared to observe which methods of smelling are universals, that is to say identical in every place and every time. Actually, according to olfactory anthropology, there are a certain number of constants, three of which I shall discuss here: 1) the persistence of smell memories linked to the importance of an original emotionalperceptive context and to the secondary semantic information imprinted along with the odor, 2) the duality of the hedonistic space, between "good» and «bad» smells, and 3) the invasive quality of olfactory stimuli, particularly when they concern human body smells or those which are associated with it.

Take the first of these invariables, the persistence of olfactory memories. In every human being, olfactory stimuli leave strong memory traces. For example, the aversion to smells of certain foods acquired in infancy can linger fifty years later ${ }^{\mathrm{iv}}$. Furthermore, each of us has our private cache of smell memories where particular odors elicit memories which are mostly plesant, sometimes unpleasant, but always very old. In short, a lot more so than our other senses, our sense of smell enables us to consolidate memories. There are many explanations for this, but it is mainly true because of the functional link between smell perception and the emotional treatment of information.

These mechanisms are still poorly understood, but we know that several regions of the brain associated with the processing of olfactory signals (the thalamus, the frontal neo-cortex, and the limbic system) bring together different kinds of sensory information, give "odor" an emotional value, and help form associations and connections, as well as playing an important role in the formation of memories (so-called engrams or neuronal traces of feeling) which of course are never purely olfactory. Indeed, at the same time as it takes in an odor, our memory stores the whole emotional and sensory context; a phenomenon referred to as the Proust Syndrome. This helps consolidate the memory trace, and is a universal response shared by all humans.

Secondly, one must also consider that the olfactory experience is structured in such a manner that one is faced with opposing odors: the "good" and the "bad". This confrontational aspect satisfies certain needs of the human spirit: it is bipolar, one might say "manichean", and it 
categorizes the world quickly and easily according to the precept of cognitive economy, which is always appreciated by our species. Aside from a few exceptions linked to individual olfactory experiences, this somewhat crude form of taxonomy is characterized by the relative invariability of the disagreeable smells, which depends very little on cultural conditioning. It is also characterized by a larger variability of agreeable smells, which are more subject to a kind of socialization of smells ${ }^{\mathrm{vi}}$ and, more particularly, to a society's food preferences. In short - without excluding cultural reinforcements - humans naturally tend to categorize certain very specific odors as "bad": those of excrement, urine, sweat, decomposition, and perhaps rank or stagnant water, and so forth.

The third invariant is the "invasive" quality of odors. According to Kant, we have to take odors with us ${ }^{\text {vii }}$. This recognized principal of olfactory perception is particularly clear in the choice of adjectives used by people subjected to olfactory environments: many odors are described as "sharp", "penetrating", or "piercing". The fact that it is difficult to shield ourselves from these odors, and the immediate access of smell to the brain, make such odors seem like intruders. They impose themselves on our bodies and open us to the outside world. And surely nobody can escape from such odors, especially odors of the human body. Powerful, dominant, and tenacious ${ }^{\text {viii }}$, they owe to their penetrating strength the fact that we easily classify them and remember them.

Take, for example, the odor of a decomposing corpse. It is an odor which is "powerful, immobilizing, nauseating, clinging", according to forensic pathologists and firemen I have talked to; it is an odor which persists in your mind no matter how hard you try to forget it. People in hospitals talk about odors in ways that evoke this feeling of assault. One nurse described her impression "of having swallowed bits of flesh exuded by bedsores and necrosis". Another nurse felt that intense odors, like those of deep infections "permeated" her clothing and her body; the odor "clung" even after a change of clothing, she said. The frequency of smells called "sharp, penetrating, piercing, or invasive" brings to mind the medical descriptions of the $16^{\text {th }}$ and $17^{\text {th }}$ centuries, when it was believed that smells could insinuate themselves into the interior of the body $^{\mathrm{ix}}$. Given the pervasiveness and tenacity of these feelings ${ }^{\mathrm{x}}$, we are justified in thinking of them as biologically determined, and specifically as precautionary strategies which establish a relationship between bad smells and toxicity. From an evolutionary standpoint this might be considered a survival strategy.

\section{CULTURAL AND INDIVIDUAL VARIABLES}

There is no question, however, that aside from these universals, there are large differences in smell perception among different groups of human beings and, even, among individuals. Once again, I shall select three of these on which to focus: 1) the qualitative and therefore personal aspects of smell perception, 2) the number and preciseness of the terms we use to describe olfactory functions, and 3 ) the motivational or cognitive dimensions of olfactory stimuli.

Stercus cuique suum bene olat, said Montaigne ("everyone thinks his own shit doesn't stink"xi - excuse my french!). This assertion reminds us that while we all smell things, we smell them in different ways $^{\text {xii }}$. Each human is unique, genetically as well as epigenetically, and for this reason the way in which we interpret smells varies from one person to another. The olfactory experience is always partly idiosyncratic. Not one of us will experience a madeleine the way Proust did. The differences beween individuals are also affected by gender: women have a more sensitive sense of smell than men, and the smells they like and dislike are also different, according to a 1986 National Geographic survey of 1.5 million people ${ }^{\text {xiii }}$. Men, for example, prefer the scents of musk and civet, maybe because there are structural similarities between civet and androsterone, the male sex hormone ${ }^{\text {xiv }}$. 
$\mathrm{Age}^{\mathrm{xv}}$ is a factor as well: our sensitivity to odors decreases as we grow old, especially after the age of seventy. Environment also plays a role, in that people who work outside have, on average, a better sense of smell than people who work in offices ${ }^{\mathrm{xvi}}$. Psychological factors can create differences: for instance, if someone is told that a certain odor is unpleasant, he or she is more likely to perceive it as unpleasant than someone who has not been warned. And certainly an individual's state of health also plays a role.

With the two other factors (so the various ways we describe smells, and the emotional and cognitive aspects of smelling) we get into something very interesting to marketing experts in the perfume industry, the cultural polarization of olfactory perception. Research has shown that differences in olfactory perception exist between certain groups ${ }^{x v i i}$, even between certain countries $^{\text {xiii }}$. For example, Germans like the smells of balsam and conifers while the French prefer floral scents ${ }^{\text {xix }}$. When it comes to olfactory categories, most West Germans file grass and forest under "nature" while the Japanese reserve that label for flowers ${ }^{\mathrm{xx}}$. The National Geographic survey found that only $63 \%$ of American men are capable of detecting the odor of androsterone as opposed to $76 \%$ of European men.

I could give many examples, but to illustrate this cultural variability I will focus on the natural language of odors, whose richness depends on the olfactory sensitivity of the cultures in question. It is said that in Western societies the lexicon for odors is weak or vague. Leaving out slang expressions, this does seem to hold true for European languages. But this is not universal. Ethnographic studies have found a much more elaborate olfactory vocabulary in many other cultures (in Muslim-Arab countries ${ }^{\mathrm{xxi}}$, among the Waanzi of Gabon ${ }^{\mathrm{xxii}}$, and the Seerer N'dut in Senegal $^{\mathrm{xxiii}}$, etc.). In France, I have found a large gap between the numbers of descriptors used by most people and the ones used in different professional milieus which require olfactory expertise. Perfumers and oenologists, for example, have a richer and more precise olfactory lexicon than, say, doctors or, moreover, the average individual. In fact, natural language tends to be "odorless" only in areas where the olfactory environment is unimportant.

People pay attention to smells when they are important to their daily lives and are not just part of the sensory and emotional background. This is certainly the case with the Umeda of New Guinea: in a tropical rainforest scent plays as important a role as sight in terms of spatial orientation $^{\text {xxiv }}$. The Waanzi in southeast Gabon use odors daily in fishing, hunting, and gathering, thanks to a kind of 'olfactory apprenticeship' in family life and rituals of initiation. In Senegal, the Ndut are even more skillful: they are able to distinguish the odors of the different parts of plants ${ }^{\mathrm{Xxv}}$ and they are able to give a name to these odors. In our society, of course, most of us are incapable of this. Thus, there is real cultural variability in the sense of smell.

To sum up, each of our olfactory experiences is based in part on universal (result of our common biology or physiology), in part on our individual genetic inheritance, and in part on cultural influences. For the latter, the variability is explainable through upbringing, alimentary habits (appetite and conditioning), cosmetic practices (the conditioning of approach and avoidance), the individual olfactory niche, familiarization ${ }^{x x v i}$ with scents and flowers (beginning with the neonatal and oftentimes prenatal period), etc. They work together to channel our innate sensory capacities. The question is, can we find something that renders our olfactory experience uniquely human?

\section{3) THE UNIQUENESS OF THE HUMAN OLFACTORY EXPERIENCE}

We can say that there is naturally and culturally a way of smelling which is specific to our species. In the first place, we must temper the assertion that evolution, in developing our cognitive 
abilities as well as our other senses, has diminished the role of our sense of smell. Certainly André Holley is right when he says that the motivational aspect of olfactory stimuli has taken precedence over the cognitive aspect. But even if smell occupies a relatively low position in the hierarchy of our senses, our olfactory apparatus is still functional; we are capable of detecting large numbers of scents, between 2000 and 4000 according to some people and up to 10,000 according to others. We are also able to detect minute traces of certain strong-smelling molecules. We can detect the scent of mercaptan at 40 billionths of a milligram per liter of air and that of feces at 4 billionths of a milligram per liter. Moreover, when a perfumer replaces even one of the myriad components of a traditional perfume, the customers protest, which proves that they have a discerning sense of smell, able to "compare and distinguish a new and incongruous nuance in a familiar scent" xxvii. Our sense of smell functions consistently at optimum levels (except, of course when we have a cold!): We actually create new olfactory cells, something that doesn't generally occur with other cells in the brain and nervous system ${ }^{\text {xxvii }}$.

Admittedly, we are far from possessing the abilities of many other animal species. We share our limited sense of smell with the advanced primates (e.g. gorillas, chimpanzees, etc.) and microcosmic ${ }^{\text {xxix }}$ mammals. Our sense of smell is much less acute than that of species that rely on odors as the main guide to their behavior or as an essential reference in their sensory environment: social insects (ants or bees), butterflies and moths, which are sensitive to pheromones (for example, certain butterflies are capable of detecting pheromones from miles away), fish, colonizing animals, and, to cite an example we're all familiar with, dogs, which are capable of detecting ten times as many odors as we are, (that is) around 100,000 all together.

However, beyond these unequal abilities, is there a big difference between the dog that smells a human and the human who smells a dog, putting aside the intrinsic qualities of the human and canina odors? I would say "yes". The difference is this: if the dog, to continue our example, can smell more molecules than the human, the human will always smell more than simply what arrives at his nose. He owes this to a cognitive ability which is his alone: a symbolic processing of sensory information, which bypasses the direct conceptual process and is particularly common when it comes to smells, through the association of ideas, metaphors, vague taxonomies, etc. I will conclude by giving two examples of this elaborate mental reaction characteristic of the human olfactory experience.

The most rudimentary way to study olfactory stimuli is to trace them to a source (the odor of stagnant water), to an effect (a nauseating odor), or to a property (a beavy odor). Often, however, we are not content to deal with stimuli as though they were in a vacuum. We are capable of looking at them in relation to each other and to different aspects of the olfactory landscape. For example, in the presence of odorous molecules, we are sensitive to what one might call the melodic line of successive stimuli. This olfactory melody is a sequence of olfactory stimuli organized in the light of the subject's predisposition to certain cultural and natural perceptions. These stimuli occur in exactly the right place in the chronology of the sensory experience. However the expected melody can at times be thrown off. Consider that in France (and in many European societies), we are accustomed to the following sequence of olfactory stimuli when sitting down to a good meal $^{\mathrm{xxx}}$ : The smell of the aperitif, perhaps anise if you are from Provence like me and drink pastis, then the scents of fish, meat, cheese, and coffee, and finally the scent of cigar. We're likely to be more or less put off if the first scent is that of a cigar, followed by cheese, fish, coffee, anise and then meat.

At the same time, we're capable of finding an olfactory harmony which can be defined as the happy co-existence of stimuli. Here, again, this anticipated harmony can be destroyed when, quite simply, the stimuli don't go together. Consider the strange reaction of the forensic 
pathologist who, in the presence of a corpse, which was "not very far along", told me he was more discomfited by the "smell of its feet" than by the smells that emerged when he cut open the body. Or another doctor who is more put off by the unpleasant smell that some people's breath has first thing in the morning than by the odor of a corpse.

These doctors discuss three different smells: foot odor, morning breath, and rotting corpse. How can we interpret their reactions? We can see one general prototype model, the disagreeable smell of the human body. Of these three odors, the first, as unpleasant as it is, is perceived as an odor of the living / whereas the other two are odors of death. The discomfort of the two forensic pathologists is related to this: in regard to the prototype "odor of death", the smell of feet (filed away in the prototype "odor of the living") is not relevant in the sense that its presence calls up feelings generally experienced in the presence of a decomposing body. In reference to the prototype "odor of the living", morning breath (which doctors seem to categorize as an "odor of death") in a living patient imposes the juxtaposition of two olfactory images which belong to radically different registers and, in this manner defy expectations. Both examples demonstrate a violation or a disturbance in our expectations of olfactory categories, which generally prevent confusion between two odorous realms- the living and the dead. A corpse ought not to have a smell of the living nor a live person the smell of death. Here we might say that rather than "a lack of discriminating taste", what we call, in French, a "faute de goût", we have "a lack of discriminating smell".

\section{CONCLUSION}

It is quite unlikely that other species are as sensitive as we are to olfactory melodies or to olfactory harmony. This is why I say that people always smell more than that which is presented to their olfactory bulb of their brain. We smell in ways that are personal and idiosyncratic, in addition to that which is socially and culturally determined. However, individual and cultural variability do not mean that all smell is relative. Our olfactory perceptions are largely determined and constrained by innate sensory and cognitive predispositions that are universal in the human brain. We don't smell just any old way and we can't smell (or can't not smell) just anything. The variability of our olfactory sensitivity is limited and for that reason so is our olfactory ability and the extent and acuity of our olfactory performance. So the olfactory experience is culturally developed but naturally constrained. It is likely that unpleasant smells, in water or any other element, are the result of this double-edged determinism which we need to be aware of if we want to do something about them.

Is it enough to be aware? I am not sure. One day I was discussing different food odors with a great chef from Nice and he insisted that a good tomato has an "honest" smell. After many years of research on odors, I still don't know exactly what an "honest" smell might be. But I can say I hope that thanks to your work you will be able to give us water that makes us say, "You know, this water has a really honest smell".

\footnotetext{
i «May God deliver me from still waters, I guard myself against running water. »

ii «Beware of still waters!»

iii Between the $6^{\text {th }}$ and the $8^{\text {th }}$ week of gestation, the olfactory bulb begins to distinguish itself and the first olfactory connection to the brain has a definitive structure by the $18^{\text {th }}$ week: Schaal B. (1997), "L'olfaction. Développement de la fonction et fonctions au cours du développement", Enfance, n. 1, p.7.

iv Ibid. p. 15

${ }^{v}$ This is also observable in other sensory realms, even when the nuances of perception are large: in every society we can find an opposition between light and dark colors, hot and cold, bitter and sweet, etc.: Dupire M. (1987), "Des goûts et des odeurs: classifications et universaux", L'Homme, XXVII (4), p.20.

${ }^{\mathrm{vi}}$ Schaal B., Rouby C., Marlier L., Soussignan R., Kontar F., Tremblay R. E. (1998) , "Variabilité et universaux au sein de l'espace perçu des odeurs. Approches inter-culturelles de l'hédonisme olfactif." In Dulau R., Pitte J.-R. (ed),
} 
Géographie des odeurs, Paris, L'Harmattan, p44. There are certain innate olfactory preferences: newborns make accepting facial expressions when confronted with the artificial scents of banana and vanilla: Schaal B., Porter R. H. (1990), “L'olfaction et le développement de l'enfant", La Rechernhe, n. 227, December, p.1507-1508.

vii Kant E. (1986), Anthropologie d'un point de vue pragmatique in CEuvres philosophiques III, Paris, Gallimard, p.976.

viii Candau J. (2001), "De la ténacité des souvenirs olfactifs", La Recherhbe, July-August, n.344, p.58-62.

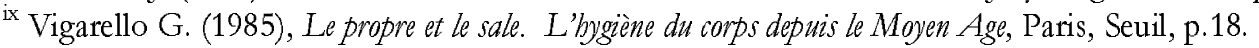

${ }^{\mathrm{x}}$ In Java, the odor of a cadaver is thought to spread death by contagion: Howes D. (1986), "Le sens sans parole: vers une anthropologie de l'odorat", Anthropologie et Sociétés, vol. 10, n. 3, p. 41. In a recent novel, Dominique Noguez described the odor of a dead old woman which touched her "like a knife" : "Odeur de sainteté", Senso, n.4, mai/juin 2002, p.130.

${ }^{\mathrm{xi}}$ Montaigne (Essais, III, 8). The idea is taken from Erasmus, Adages, III, Chap.II.

xii Lecoeur F., Rosselin C. (1999), "Nez à nez" in Julien M.-P., Warnier J.-P. (ed), Approches de la culture matérielle. Corps à corps avec l'objet, Paris, L'Harmattan, p.95.

xiii Gilbert A. N., Wysocki C. J. (1987), “The Smell Survey: Results”, National Geographic Magazine, vol. 172, n. 4, Oct. , p. 514-525.

xiv Dupire M., Ibid. p.10.

${ }^{\mathrm{xv}}$ Perchec C. (1999), "Les modèles de la mémoire: revue des études sur l'olfaction et proposition d'un modèle de la mémoire olfactive", Informations sur les Sciences Sociales, vol. 38, n.3, p.445.

${ }^{\mathrm{xvi}}$ The olfactory system, being changeable, is susceptible to influences of chemical post-natal environment: "rats raised in an odorless environment developed atrophied olfactory bulbs (compared to those rats raised in a normal environment ) and demonstrated a reduction in physiological and behavioral response to odors": Schaal B., "L'olfaction: développement de la fonction et fonctions au cours du développement". Ibid. p.10.

${ }^{x v i i}$ Classen C. (1993), Worlds of Sense, London, Routledge.

xviii Gilbert A.N., Wysocki C.J., Ibid.

${ }^{\text {xix }}$ Pitte J.-R. in Dulau R., Pitte J.-R., Ibid., p. 10.

${ }^{x x}$ Rouby C., Sicard G. (1997), "Des catégories d'odeurs", in Dubois D. (ed), Catégorisation et cognition: de la perreption an discours, Paris, Éditions Kimé, p.70.

xxi In her attempt to classify Arab-Muslim odors, F. Aubaile-Sallenave (1999) gathered over 250 terms from dictionaries and from literature referring to odors and to perfumes, in areas as varied as sensuality, morality, aesthetics, religion, and so on: in Musset D., Fabre-Vassas C. (ed), Odeurs et parfums, Paris, Éditions du C.T.H.S., p.96.

xxii Mouélé M. (1997), "L'apprentissage des odeurs chez les Waanzi: note de recherches", Enfance, n.1, p.209-222.

xxiii Dupire M., Ibid.

${ }^{x x i v}$ Classen C., Howes D., Synnott A. (1994), The Cultural History of Smell, London, Routledge, cited by Tyler S. A. (1996) in American Anthropologist, vol. 98, n.3, Sept., p.618. Don't forget that in his Natural Historiy (XII, 86) Pliny the Elder tells that Alexander the Great sensed Arabia from the middle of the ocean by the "indescribable perfume of the many wind-borne aromas".

${ }^{x x v}$ Dupire M., Ibid. p.14.

${ }^{x x v i}$ Subjects tend to classify unfamiliar scents as unpleasant or neutral rather than as agreeable: Perchec C., Ibid. p.454.

xxvii Holley A (1999)., Éloge de l'odorat, Paris, Odile Jacob, p.8.

xxviii See article "Neurones à volonté" (2000) in La Recherrbe, n.329, March, p.28-44.

xxix As opposed to "macrocosmic" mammals (marsupials, insectivores, carnivores, rodents) gifted with a very complex olfactory organ: Brossut R. (1996), Phéromones. La communication chimique chez les animaux, Paris, CNRS Éditions, 1996, p. 53-54.

${ }^{\mathrm{xxx}} \mathrm{I}$ am generalizing horribly in an effort to make a point. Of course, this would apply to the majority of occidental societies. 